\title{
CENTENÁRIO DO BACHARELADO DE MARIA AUGUSTA SARAIVA.
}

\author{
Marcelo de Alcântara' \\ Aluno do Curso de Graduação da Faculdade de Direito da \\ Universidade de São Paulo
}

\begin{abstract}
“(...) Ora, a mais inelutável de todas as influências que atuam sobre a formação da natureza humana, em todos os seus elementos, é a mulher. Mãe, amante, esposa, filha, mestra, ela é a explicação do individuo e da sociedade.(...) todos os extremos, todos os sacrificios, todas as honras do Estado são poucas para a educação feminil, e a proclamação da igualdade dos dois sexos perante o ensino impõe-se como a legenda suprema de nossa propaganda. (...) a educação da mulher contém em si a educação do povo, como a terra mãe contém no seio o mundo infinito da vegetação, que a cobre, desde a rasteira graminea dos prados até às selvas desafiadoras da tormenta. (...) A mulher envolve e domina a esfera humana, como a safira diáfana do firmamento envolve e domina a esfera terrestre. "2
\end{abstract}

(Rui Barbosa)

Ivette Senise Ferreira e Ellen Gracie Northfleet. Faculdade de Direito do Largo de São Francisco e Supremo Tribunal Federal. Tradição, continuidade, perpetuação, perenidade e também inovação, rompimento, mudança, inconformismo. Da união dessas palavras extrai-se um único sentido, representado por inúmeros vocábulos: pioneirismo, prenunciação, vanguardismo, ou melhor, Maria Augusta Saraiva.

O Supremo Tribunal Federal ${ }^{3}$. pela primeira vez em sua história, desde 1828, quando foi criado, possui uma mulher, Ellen Gracie Northfleet, nomeada no ano

1. Esta singcla contribuição às memórias acadêmicas somente foi possivcl graças ao empenho do Serviço Téenico de Imprensa - Sç̧ão de Arquivo c Muscu - da Faculdade de Dircito da USP, especialmente Waldir Willian Mcrisci c Antonio Augusto Machado de Campos Neto.

2. O Desenho e a Arte Industrial - Discurso Pronunciado no Sarau Artistico-Litcrário que a dirctoria c professorcs do Liccu de Artes c Oficios dedicaram ao Exmo. Sr. Consclheiro Rodolfo Epifânio de Souza Dantas cm 23 de novembro de 1882, in Obras Completas de Rui Barbosa, v. 9, t. 2, Rio de Janciro, Ministćrio da Educação c Saúde, 1948, p. 263-4.

3. No periodo imperial, cra denominado Supremo Tribunal de Justiça. Cf. Breve Histórico, disponivel [on line] in http://www.stf.gov.br/institucional/ministros/Breve.asp [01-05-2002]. 
de 2000. Na ordem de antigüidade, ela é a $153^{\circ}$, a primeira mulhel entre os 152 ministros ${ }^{4}$ que já passaram pelo Supremo Tribunal Federal (período Republicano).

Já a Faculdade de Direito do Largo de São Francisco, de 1827, com José Arouche de Toledo Rendon, a 1998, com Álvaro Villaça Azevedo, foi dirigida por 36 homens. ${ }^{5}$ A professora titular Ivette Senise Ferreira foi eleita em 1998, tornando-se a primeira mulher a dirigir a Faculdade de Direito do Largo de São Francisco, escola criada em 11 de agosto de 1827 e onde se graduaram 653 dos 153 ministros que já integraram o Supremo Tribunal Federal.

Qual a relação entre Maria Augusta Saraiva, a primeira bacharela paulista, que colou grau na Faculdade de Direito do Largo de São Francisco em 3 de maio de 1902, qual a relação existente entre ela e a hodierna transformação social?

As mulheres que hoje rompem preconceitos, destacando-se em posições sempre antes ocupadas por homens, quer nos tribunais, quer nas universidades, quer na política, quer nas empresas, nas fábricà, nos escritórios, são as mesinas que, lado a lado com os concorrentes de hoje, ocupavam os bancos universitários há algumas décadas, enfrentando semelhantes obstáculos - embora passassem despercebidos -, em um momento de formação profissional, social e cultural.

Aquelas poucas acadêmicas não se sentiam discriminadas, porque viviam de acordo com os valores predominantes na época. Isso foi o que concluiu Cleide Maria Bocardo Cerdeira, ${ }^{7}$ em recente tese de doutorado defendida na Faculdade de Filosofia, Letras e Ciências Humanas da USP. Afirma a pesquisadora" que "essas mulheres estavam imersas nos valores vigentes" e que "provavelmente desenvolveram uma atitude ambigua perante a questão da discriminação". A pesquisa baseou-se nas entrevistas de inúmeras professoras da USP, o que levou a estudiosa" a considerar que “como o conceito de discriminação é mais recente, nas entrevistadas, o que aparece é

4. Ordem de Antigüidade disponível [on line] in http://www.stf.govbr/institucional/ministros [0।05-2002]. Na verdade, passaram pelo STF, antes de Ellen Gracic Northtlect, 151 ministros diferentes, pois Josć Francisco Rczek foi nomcado duas vezes para o cargo de Ministro do STF. Tomou posse pela primcira vez cm 24 de março de 1983. Renunciou ao cargo cm 14 de março de 1990, scndo nomcado, no dia scguinte, Ministro de Estado das Relações Extcriores. Auxiliou o Presidente da República até 13 de abril de 1992, e no dia 4 de maio de 1992 foi nomeado novamente para o cargo de Ministro do STF, tomando possc no dia 21 do mesmo mês. (Cf. biografia, disponivel [on line] in http://www.stf.gov.br/ institucional/ministros/republica.asp?'cod_min=139 [06-05-2002].)

5. Cf. Revista da Faculdade de Direito - Universidade de São Paulo, v. 92, 1997, pp. 495-530.

6. O númcro corresponde a mais de um terço $(34,6 \%)$ dos ministros que passaram pelo STF no período Republicano.

7. Cf. O ensino superior e a mulher - Aspectos da presença feminina na Universidade de São Paulo nas décadas de 1930 a 1950. Tcse (Doutorado), Faculdade de Filosofia, Letras c Ciĉncias Humanas da USP, São Paulo, 200I, pp. I-I 44.

8. Cf. $O$ ensino superior cit. (nota 6 supra), p. 141.

9. Cf. $O$ ensino superior cit. (nota 6 supra), p. |4I. 
um esforço quase que de negação desse tipo de obstáculo" e que "elas são pioneiras 'malgré elles mêmes"'

Dentro da nossa Universidade é possível verificar a evolução da presença das mulheres ao longo dos anos, principalmente na Faculdade de Direito, na de Medicina e na Escola Politécnica. Nesta, criada em 1894, apenas 1,3\% dos formandos, até a década de 50, eram mulheres. Os homens correspondiam a 98,7\%. ${ }^{10}$

A Faculdade de Medicina, criada em 1912 e regulamentada em 1913, teve na sua primeira turma, em 1918, 26 homens e apenas duas mulheres. Até 1969, o número de homens formados era de 3.281 (91,26\%), enquanto o de mulheres era de $314(8,74 \%)^{\prime \prime}$

Nesta Academia de Direito, $99,1 \%$ dos bacharéis formados na década de 20 eram homens, e $0,9 \%$, mulheres. Na década de 40 , a percentagem aumentou para $3,3 \%$, contra $96,7 \%$. Na década de 60 , as mulheres já representavam dım quinto dos bacharéis, ou seja, $20,6 \%$, e os homens, $79,4 \% .^{12}$

Atualmente, as mulheres, que são maioria no nosso Pais, representañdo $50,78 \%$ dos brasileiros ${ }^{13}$, disputam igualmente com os homens os bancos universitários. .Na turma de 2000 desta Faculdade, por exemplo, ${ }^{14}$ dos 384 bacharéis, 45,3\% eram mulheres e $54,7 \%$ eram homens, percentagem bem distante daquela apresentada na década de 20. As pequenas diferenças certamente estão relacionadas com a opção de curso, com a preferência de carreira entre os gêneros.

A presença feminina na direção de tradicionais instituições acadêmicas do Largo de São Francisco também é muito recente, como no caso do Centro Acadêmico XI de Agosto. Desde 1903, da $1^{\text {a }}$ Diretoria, cujo presidente foi Pedro Doria, até a 95", apenas homens comandaram o ilustre Centro Acadêmico. A primeira presidente foi Andrea Maria dos Santos Mustafa, em 1998, na 96" Diretoria do C. A. XI de Agosto ${ }^{15}$

E a nossa homenageada? Por que é tão desconhecida no meio acadêmico, no meio social e até no meio jurídico, se foi a precursora das mulheres? Realmente, pouco se sabe sobre a sua vida.

Maria Augusta Saraiva nasceu no interior paulista, em São José do Barreiro, cidade próxima à divisa com o Estado do Rio de Janeiro e distante cerca de

10. Cf. $O$ ensino superior cit. (nota 6 supra), p. 91.

11. Cf. $O$ ensino superior cit. (nota 6 supra), p. 92.

12. Cf. $O$ ensino superior cit. (nota 6 supra), p. 91.

13. Segundo o Censo 2000, do IBGE, a população brasilcira ć de 169.799 .170 de habitantes, sendo $83.576 .015(49,22 \%)$ de homens c $86.223 .155(50,78 \%)$ de mulheres. Disponivel [on line] in http:// www.ibge.gov.br/home/estatistica/populacao/censo2000/default.s/tm [17-04-2002].

14. Cf. Armando Marcondes Machado Júnor, Centro Acadêmico XI de Agosto-Faculdade de Dircito de São Paulo, 5" v., $4^{4}$ cd., São Paulo, Magcart, 200I, pp. 2147-5I.

15. Cf. A. M. Machado Júnor, Centro Acalềmico cit. (nota 13 supra), pp. 2.219-21; cf. também ANa Luiza Martins - Heloisa Barbuy, Arcadas - História da Faculdade de Direito do Largo de São Francisco: 1827-1997. São Paulo, Alternativa, 1998, p. 127. 
260 quilômetros de São Paulo. A filha do major Joaquim José Saraiva e de Leopóldina Maria Saraiva viveu em Araraquara e em Rio Claro, onde estudou no renomado Colégio Inglês. ${ }^{16}$

Quando adolescente veio para São Paulo, e já se mostrava uma excelente aluna. No seu histórico escolar possuia onze certificados de exames, sendo sete expedidos pelo "Curso Anexo à Faculdade de Direito de São Paulo" e quatro pela Secretaria de Estado dos Negócios do Interior de São Paulo. Foi aprovada com distinção em História do Brasil, em História Natural e em Física e Química, e plenamente com louvor em História Universal. ${ }^{17}$

Concluídos os exames preparatórios, dirigiu um requerimento escrito a mão, datado de 8 de março de 1898, ao Diretor da Faculdade de Direito do Largo de São Francisco, pedindo-lhe que fosse matriculada. Quatro dias depois, em 12 de março, o Diretor dava o seguinte despacho: "Matricule-se."18

Nesse requerimento, a candidata afirmava que havia nascido em 31 de janeiro de 1878. Contudo, do seu prontuário, armazenado no Arquivo da Faculdade, e também no Registro de Cartas dos Bacharéis (Livro de Registro dos Diplomas), consta que ela nasceu em 31 de janeiro de 1879. Parece dificil aceitar tenha a nossa pioneira confundido $o$ ano do próprio nascimento, quando redigiu o requerimento.

Os registros da Faculdade provavelmente se apoiaram em uma certidão de idade, ${ }^{19}$ com data de 10 de março de 1898 , fornecida por um vigário de São José do Barreiro, que transcreve um termo registrado no assento de batizados. Eis o teor transcrito:

"Aos onze de Setembro de mil oitocentos e setenta e nove batizei (...) Maria, nascida a 31 de Janeiro do corrente ano, filha do Capitão Joaquim José Saraiva e de D. Leopoldina Maria Saraiva (...)"

Na certidão, que faz parte do prontuário da aluna arquivado na Faculdade, a palavra "nove" tem aparência de rasura. Não se sabe se o vigário, ao transcrever o termo existente no assento de batizados, errou, ou se o ano de nascimento registrado neste é mesmo 1879. Fica a indicação para que dedicados pesquisadores, que tenham possibilidade de localizar o Livro de Assento de Batizados, de São José do Barreiro, daquela época, possam desvendar o mistério.

A jovem esforçada, logo no primeiro ano de curso, já se destacava nos estudos. Foi aprovada, com distinção, no dia 23 de novembro de 1898, nas matérias do

16. Cf. Histórico da Patrona, claborado pela Sccrctaria de Estado da Educação (SP) c fornecido pela Dirctoria da Escola Estadual de Ensino Fundamental Dra. Maria Augusta Saraiva (não-publicado).

17. Cf. Histórico Escolar, que integra o prontuário da aluna Maria Augusta Saraiva arquivado na Faculdade de Dircito da Universidade de Sào Paulo.

18. Cf. prontuário cit. (nota 16 supra).

19. Cf. prontuário cit. (nota 16 supra). 
respectivo ano, que eram Filosofia do Direito, Direito Romano e Direito Público e Constitucional. ${ }^{20}$

No quarto ano, em 1901, também foi aprovada com distinção, no dia 22 de novembro de 1901, nas duas matérias de cursou, que foram Direito Civil e Direito Comercial. ${ }^{21}$

Aprovada nas duas matérias que lhe faltavam para matricular-se no quinto ano, Maria Augusta Saraiva dirigiu requerimento ao Diretor da Faculdade, em 28 de fevereiro de 1902, pedindo que fosse inscrita na lista dos candidatos ao exame do quinto ano. No mesmo dia, foi exarado o seguinte despacho: "Inscreva-se. "22

E no dia 29 de abril de 1902 foi aprovada, novamente com distinção, em Teoria do Processo Civil, Comercial e Criminal, em Medicina Pública, em Direito Administratiṿo e em Legislação Comparada sobre Direito Privado. ${ }^{23}$ Estava pronta para receber o grau de bacharel.

Sábado, 3 de maio de 1902. Uma hora da tarde. Aparentemente um dia normal. Mais uma cerimônia de colação de grau da Faculdade de Direito. Não. Era um dia especial, e a emoção do momento somente pode ser narrada por quem lá estava:

"O vasto edificio da Faculdade, - vestíbulo e corredores - caprichosa e elegantemente ornamentado de folhagens e flores, apresentava um aspecto garrido de festa, que ainda mais se acentuava com o movimento extraordinário de convidados e alunos daquele estabelecimento.

"Uma seção da banda de música da brigada policial, antes e durante a solenidade, executou várias peças.

"(...) avultado número de senhoras, cavalheiros, representantes do Seminário Episcopal e acadêmicos, o dr. Vicente Mamede de Freitas ${ }^{24}$, diretor interino da Faculdade, deu começo à cerimônia, mandando o secretário, dr. Júlio Maia, proceder à leitura do resultado dos exames do $5^{\circ}$ ano. $" 25$

Após a intervenção de Júlio Joaquim Gonçalves Maia, secretário da Faculdade, subiu à tribuna o acadêmico Luiz Gonzaga Mendes de Almeida, orador da turma, e pronunciou um discurso "muito apreciado e coberto de aplausos" 26 A

20. Cf. Histórico do Curso Superior; que integra o prontuário da aluna Maria Augusta Saraiva arquivado na Faculdade de Dircito da Universidade de Sào Paulo.

21. Cf. Histórico cit. (nota 12 supra).

22. Cf. prontuário cit. (nota 16 supra).

23. Cf. Histórico cit. (nota 19 supra).

24. Vicente Mamede de Freitas foi Dirctor da Faculdade cntrc 1904 c 1908.

25. O Estado de São Paulo, Domingo, 04 de maio de 1902, p. 1.

26. O Estado cit. (nota 24 supra), p. 1. 
importância daquele dia era conhecida dos alunos, como se pode notar no seguinte trecho do discurso do orador da turma:

"Há entre nós uma bacharelanda, uma distinta colega, que soube provar. que o direito, esse poder moralmente inviolável, pode perfeitamente ser estudado pela mulher. Se a energia do homem é necessária para manter a aplicação do direito, não menos uitil, para determiná-lo, aconseliá-lo, testemunhá-lo, é a delicadeza do coração da mulher. Seja ela o aviso contra o rigor das leis, quando se tornar oportuna a aplicação da eqüidade. Seja ela a conselheira das noivas para o regimen do casamento; seja ela a conselheira da viúva na direção dos órfãos; seja ela a conselheira da testadora na forma das disposições de última vontade; seja ela a voz defensora dos infelizes que caem na loucura do crime. Seja ela, em suma, a testemunha de que nesta Faculdade, acima dos direitos do homem, nós colocamos os direitos da mulher; pois exmas. senhoras, ficai certas, o homem por mais forte que seja, Sansão, Holophernes, Marco Antonio, ou quem quer que for, será sempre aquilo que a mulher quiser que ele seja."27

Terminado o discurso, realizou-se a cerimônia de colação de grau dos quinze alunos, quatorze homens e uma mulher, ou melhor, a mulher.

Após essa cerimônia, teve a palavra o professor Brasílio Machado, paraninfo da turma, que demonstrou no trecho final de seu discurso que também entre os professores aquele dia não representava somente a formatura de mais uma turma. Pregou o lente:

"No meio de vós, e pela primeira vez nesta Faculdade, veio uma senhora compartir o prêmio alcançado, e trazer o contingente de sua fraqueza, que é uma força, para a obra viril da restauração do direito.

"Bem-vinda seja!

"Aos primeiros movimentos revolucionários de 89, Mirabeau instava com os seus conjurados:

"Nossa vitória depende do concurso da mulher!

"E a revolução destruiu o direito.

"Por que não poderemos nesta hora dizer também:

"Vinde, senhora. Não se trata mais de destruir o direito, mas de reconstruir o direito.

"Nossa missão precisa do concurso da mulher. ${ }^{23}$

\section{7. $O$ Estado cit. (noti 24 supra), p. I.}

28. O Estado cil. (nota 24 supra), p. 2, c também Correio Paulistano, Domingo, 04 de maio de 1902 , p. 3 . 
A partir desse dia, o futuro era todo da brilhante bacharela. ${ }^{29}$ Iniciou a vida forense no escritório do irmão, José Joaquim Saraiva Júnior. Defendeu alguns réus na tribuna, em São Paulo e em Jaboticabal, conseguindo-lhes a absolvição. ${ }^{30}$ Agora era buscar a glória em uma carreira tão respeitada e admirada na "República Velha" Magistratura, docência no ensino superior, política, diplomacia, para, quem sabe, um dia alcançar o Supremo Tribunal Federal.

Não; nada disso. Nada de esplendor, nada de brilho. Estava decidida a emprestar o seu talento à formação das crianças. Com esse intuito é que fundou em São Paulo o Colégio Paulistano, estabelecimento de ensino secundário para moças que se destacou no início do século passado. ${ }^{31}$

Porém, logo foi obrigada a transferir o comando do colégio, pois teve de mudar-se para o Rio de Janeiro, onde seu irmão foi nomeado juiz municipal. Mas o sonho do magistério não a abandonou. ${ }^{32}$

Retornando a São Paulo, não lhe permitiram exercer o magistério oficial, porque lhe faltava a formação pedagógica. Matriculou-se então na Escola Normal da Praça - Instituto de Educação "Caetano de Campos", diplomando-se em 1918. Terminado o curso, ingressou através de concurso público no quadro de professores do ensino primário oficial do Estado de São Paulo, permanecendo até 1947. Antes de aposentar-se foi nomeada Consultora Juridica do Estado. Maria Augusta Saraiva morreu no dia 28 de setembro de 1961, em São Paulo. ${ }^{33}$

A bacharela que sonhava em ser professora primária recebeu justa homenagem, pela sua dedicação à educação paulista, através da Lei Estadual n. 8.469, de 4 de dezembro de 1964, que lhe perpetuou o nome em um educandário do bairro da Bela Vista. A "Escola Estadual de Ensino Fundamental Dra. Maria Augusta Saraiva" na Rua Major Diogo, 200, é símbolo da humildade, da modéstia da "doutora" que trocou o foro pela grandeza, pela magnitude, pela sublimidade do ensino das primeiras letras.

Certamente, as transformações sociais por que passamos atualmente, com o pioneirismo de inúmeras mulheres, seja no Brasil, seja em qualquer lugar do mundo, não foram fruto do acaso, tampouco do momento, mas foram sim reflexo da coragem, da ousadia, do destemor, da bravura, da perseverança de mulheres como Maria Augusta Saraiva, que enfrentaram o determinismo de sua época e demonstraram que as diferenças entre os gêneros humanos são qualidades, são virtudes, que se completam, para o crescimento, o desenvolvimento, o aperfeiçoamento da Humanidade, e não fatores que delimitam a capacidade.

29. O diploma de Maria Augusta Saraiva foi registrado e expedido somente em 5 de novembro de 1914.

30. Cf. Histórico da Patrona cit. (nota 15 supra).

31. Cf. Histórico da Patrona cit. (nota 15 supra).

32. Cf. Histórico da Patrona cit. (nota 15 supra).

33. Cf. Histórico da Patrona cit. (nota 15 supra). 
Que a igualdade humana, com todas as suas diferenças, vença o preconceito e a discriminação; que as perspectivas e as ambições que um título pode trazer não se transformem em vaidade, em vanglória, em altivez; que o ideal nunca se perca, por mais enevoado que esteja o futuro; que em vez da cor, o caráter, em vez do sexo, a honestidade, em vez da raça, o respeito, em vez da religião, o esforço, sejam os determinantes do sucesso, da felicidade. Por fim, que o legado de Maria Augusta Saraiva, a prenunciadora das bacharelas deste século, seja preservado, seja esmerado, seja difundido. É o que esperamos.

São Paulo, maio de 2002. 